\title{
Pengembangan Aplikasi Konversi Video Digital Greyscale Menjadi Video Digital Berwarna Dengan Menggunakan Metode Global Image Matching
}

\author{
Ketut Widiantara ${ }^{1}$, Made Windu Antara Kesiman ${ }^{2}$, I Made Gede Sunarya ${ }^{3}$ \\ Jurusan Pendidikan Teknik Informatika \\ Universitas Pendidikan Ganesha \\ Singaraja, Bali \\ E-mail: widian45@yahoo.com¹,dekndu@yahoo.com²,imadegedesunarya@gmail.com³
}

\begin{abstract}
Abstrak-Penelitian ini bertujuan untuk merancang dan mengimplementasikan sebuah aplikasi yang dapat mengkonversi video digital greyscale menjadi video digital berwarna secara cepat, mudah dan hasil pewarnaan yang memuaskan. Input dari aplikasi ini berupa video greyscale dan citra warna acuan, dan output dari aplikasi ini adalah sebuah video berwarna dengan nuansa warna yang mengacu pada citra warna acuan yang di-input-kan.

Aplikasi ini dikembangkan dengan menggunakan metode Global Image Matching yang diimplementasikan pada lingkungan bahasa pemrograman Java dengan menggunakan editor NetBeans 7.2.1. Pada aplikasi yang dibuat terdapat tiga proses utama yaitu proses ekstrak video, proses pewarnaan, dan proses render. Proses ekstrak merupakan proses memecah video menjadi frameframe dan audio. Proses pewarnaan merupakan proses yang mengimplementasikan metode Global Image Matching, dimana frame-frame hasil ekstraksi akan dilakukan pewarnaan pada proses ini. Sedangkan proses render merupakan proses penggabungan frame-frame hasil pewarnaan dengan file audio hasil ekstraksi menjadi sebuah video berwarna. Berdasarkan hasil pengujian, aplikasi konversi video digital greyscale menjadi video digital berwarna ini dapat melakukan proses konversi dengan sangat mudah dan cepat.
\end{abstract}

Kata kunci-Citra Warna Acuan, Ekstraksi , Frame, Global Image Matching,Java, NetBenas, Rendering, Video Digital Greyscale.

Abstract-This research aims to design and implement an application that could convert a greyscale video into a colored video digital, easily and staining results were satisfactory. Input from the applications is greyscale video and color reference image, and the output of this application was a videocolored with shades of color that refers to the reference image input.
This application was developed by using the method of Global Image Matching was implemented in the Java programming language environment with editor used NetBeans 7.2.1. On an application made there were three main processes that extract the video, the process of coloring, and render process. The extract process was the process of breaking into the video and audio frames. Coloring process was a process that implements the Global Image Matching method, in which frame-frame extraction results would be coloring in this process. While the render process was the process of combining frames staining results with the extracted audio files into a videocolored. Based on test results, greyscale digital video conversion application to digital video color conversion process can be done very easily and quickly.

Keywords - Color Reference Image, Extraction, Frame, Global Image Matching, Java, NetBeans, Rendering, Greyscale Digital Video.

\section{PENDAHULUAN}

Video greyscale merupakan video yang tersusun dari frame-frame yang hanya memiliki satu nilai kanal pada setiap pixel, dengan kata lain $R E D=G R E E N=B L U E$. Video greyscale sering disebut sebagai video hitam putih (black and white), ini disebabkan karena video greyscale pada tiap pixelframe-nya berwarna dari hitam sampai putih. Umumnya video greyscale kurang memiliki daya tarik jika dibandingkan dengan video berwarna (true color), ini disebabkan karena warna pada gambar video berwarna merupakan powerful descriptor yang sering digunakan untuk pengenalan objek maupun ekstraksi objek dari suatu citra. Selain itu kebanyakan video greyscale yang ada berkaitan dengan sejarah dari suatu peristiwa. Video seperti ini tentunya sangat 
penting untuk kita simak, akan tetapi dengan warna video yang greyscale menjadikan video greyscale kurang menarik untuk disimak. Untuk itu suatu upaya restorasi video diperlukan untuk mengubah video greyscale menjadi video berwarna. Restorasi yang mungkin dilakukan yaitu mewarnai video greyscale dengan menggunakan teknik pentransferan warna.

Pentransferan warna dapat dilakukan dengan cara manual, yaitu dengan menggunakan software desain grafis untuk mewarnainya. Seperti yang kita ketahui fps (frame rate/seconds) dari suatu video berkisar 25-30 fps [1]. Bisa dibayangkan waktu yang dibutuhkan untuk memproses video yang berdurasi 60 detik/ lebih akan membutuhkan waktu yang lama. Selain itu, agar hasil pewarnaan frame lebih bagus maka dibutuhkan tenaga ahli yang paham mengenai proses pewarnaan frame pada perangkat lunak desain grafis, dan untuk mendatangkan tenaga ahli tentunya membutuhkan biaya yang tidak sedikit.

Berdasarkan permasalahan tersebut perlu dikembangkannya suatu aplikasi yang dapat mengkonversi video digital greyscale menjadi video digital berwarna. Aplikasi yang dikembangkan diharapkan dapat melakukan pewarnaan pada video greyscale dengan baik, mudah, cepat, dan hasil dari konversi video ini mampu memberikan persepsi yang jelas dan lebih menarik untuk disimak.

\section{KAJIAN TEORI}

\section{A. Citra Digital}

Citra menurut kamus Webster, adalah suatu representasi, kemiripan, atau imitasi dari suatu objek atau benda. Citra merupakan istilah lain untuk gambar sebagai salah satu komponen multimedia yang memegang peranan penting dalam informasi visual. Citra mempunyai karakteristik yang tidak dimiliki oleh data teks yaitu citra kaya dalam informasi.

Suatu citra dapat didefinisikan sebagai fungsi $f(x, y)$ berukuran $\mathrm{M}$ baris dan $\mathrm{N}$ kolom, dengan $\mathrm{x}$ dan y adalah koordinat spasial, dan amplitudo $f$ di titik koordinat $(\mathrm{x}, \mathrm{y})$ dinamakan intensitas atau tingkat keabuan dari citra pada titik tersebut, jika nilai $\mathrm{x}, \mathrm{y}$, dan nilai amplitude $f$ secara keseluruhan berhingga (finite) dan bernilai diskrit maka dapat dikatakan bahwa citra tersebut adalah citra digital [2].

Citra terbagi menjadi 2 yaitu :

a. Citra diam, adalah citra tunggal yang tidak bergerak. b. Citra bergerak (video) adalah rangkaian citra diam yang ditampilkan secara beruntun sehingga memberi kesan pada mata kita sebagai gambar yang bergerak.

\section{B. Jenis Citra}

Berdasarkan nilai pixel dalam, jenis citra dapat dibedakan sebagai berikut [2].

a) Citra biner, merupakan citra dengan nilai pixel antara intensitas maksimum dan intensitas minimum. Citra biner juga disebut sebagai citra B\&W (black and white) atau citra monokrom.

b) Citra greyscale, merupakan citra digital yang hanya memiliki satu nilai kanal pada setiap pixel, dengan kata lain nilai bagian RED = GREEN = BLUE. Nilai tersebut digunakan untuk menunjukan tingkat intensitas. Warna yang dimiliki adalah warna dari hitam, keabuandan putih.

c) Citra warna, adalah citra dengan lebih dari 1 nilai pada setiap pixelnya. Warna merah, hijau, dan biru (Red, Green, Blue atau RGB) adalah warna primer untuk mencampur cahaya yang disebut dengan additive primary color yang berbeda dengan subtractive primary color untuk mencampur cat (Cyan, Magenta, Yellow).

\section{Video Digital}

Video merupakan gabungan gambar-gambar mati yang dibaca berurutan dalam suatu waktu dengan kecepatan tertentu. Gambar-gambar yang digabung tersebut dinamakan frame dan kecepatan pembacaan gambar disebut dengan frame rate, dengan satuan fps(frame per second). Karena dimainkan dalam kecepatan yang tinggi maka tercipta ilusi gerak yang halus, semakin besar nilai frame rate maka akan semakin halus pergerakan yang ditampilkan [3].

Karakteristik dari video digital mempengaruhi kualitas terhadap suatu video. Adapun karakteristik yang dimiliki oleh suatu video ada tiga yaitu resolusi, kedalaman bit, dan laju frame [4].

\section{FFmpeg}

FFmpeg adalah program komputer yang dapat merekam, mengkonversikan dan streaming audio dan video digital dalam berbagai format. FFmpeg merupakan aplikasi command line yang terdiri dari kumpulan pustaka perangkat lunak bebas/open source. Termasuk libavcodec, library untuk audio 
codec/video codec yang digunakan oleh beberapa proyek lain, dan libavformat, library untuk audio/video mux kontainer dan demux kontainer. Nama proyek yang berasal dari grup video standar MPEG, di tambahkan "FF" untuk "fast forward" [5].

FFmpeg dikembangkan pada Linux, tetapi dapat dikompilasi di banyak sistem operasi, termasuk Apple Inc Mac OS X, Microsoft Windows dan AmigaOS. Sebagian besar platform komputasi dan set instruksi arsitektur microprocessor juga di dukung, seperti x86 (IA-32 dan x86-64), PPC (PowerPC), ARM, DEC Alpha, SPARC, dan arsitektur MIPS.

\section{E. Global Image Matching}

Pentransferan warna secara keseluruhan dari gambar warna ke gambar greyscale dapat dilakukan dengan mencocokan tingkat kecerahan dan informasi tekstur diantara kedua gambar [6]. Lebih lanjut, teknik ini dikembangkan dengan memperbolehkan pengguna untuk mencocokan area dari kedua gambar dengan menggunakan kotak-kotak contoh (swatches). Teknik ini dapat diterapkan pada gambar yang bermacam-macam, dengan tekstur dan tingkat kecerahan yang benarbenar berbeda dengan sukses.
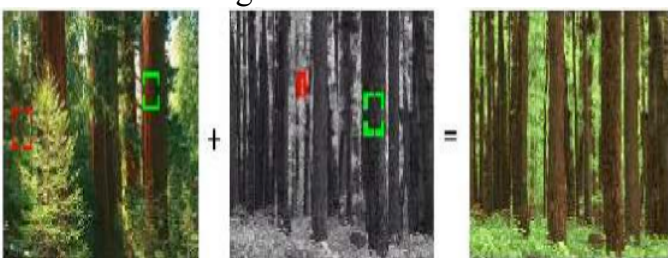

Gambar 1. Transfer Warna dengan Swatches [7]

Teknik pentransferan warna tanpa swatches merupakan teknik pentransferan warna dimana warna-warna yang akan ditransfer dari citra warna ke dalam citra greyscale ditentukan secara otomatis oleh komputer. Komputer akan mencocokkan setiap sampel warna yang diperoleh dari citra warna ke dalam citra greyscale dengan acuan tingkat kecerahan warna. Salah satu metode yang menerapkan konsep pentransferan warna tanpa swatches adalah metode Global Image Matching.
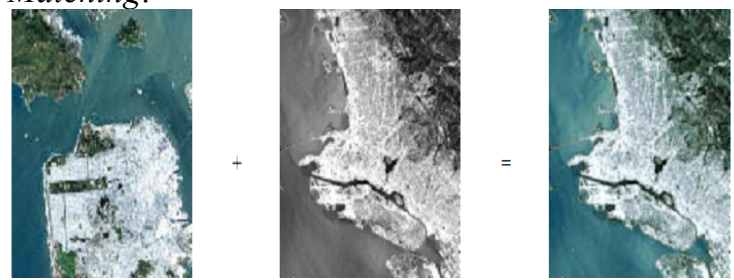

Gambar 2.14 Transfer Warna dengan Tanpa Swatches [7]

Ada beberapa tahapan yang harus dilakukan dalam proses pentransferan warna dengan menggunakan teknik Global Image Matching [8]. Berikut akan dijelaskan tahapan-tahapan dari metode Global Image Matching.

\section{a) Merubah Ruang Warna RGB ke dalam Ruang Warna $l \alpha \beta$}

Ruang warna $l \alpha \beta$ merupakan ruang warna yang dikembangkan oleh Ruderman. Ruang warna ini memiliki 3 buah channel dimana $l$ merupakan luminance, komponen $\alpha$ merupakan komponen penyusun warna yaitu dari kuning sampai biru dan komponen $\beta$ merupakan komponen penyusun warna yaitu dari merah sampai dengan hijau. Cara untuk mengubah citra dengan ruang warna RGB menjadi citra dengan ruang warna $l \alpha \beta$, dapat menggunakan matriks konversi sebagai berikut.

\section{$\left[\begin{array}{c}L \\ M \\ S\end{array}\right]=\left[\begin{array}{lll}0.3811 & 0.5783 & 0.0402 \\ 0.1967 & 0.7244 & 0.0782 \\ 0.0241 & 0.1288 & 0.8444\end{array}\right]\left[\begin{array}{l}R \\ G \\ B\end{array}\right] \ldots .(1)$}

$\left[\begin{array}{l}\iota \\ \alpha \\ \beta\end{array}\right]=\left[\begin{array}{ccc}\frac{1}{\sqrt{3}} & 0 & 0 \\ 0 & \frac{1}{\sqrt{6}} & 0 \\ 0 & 0 & \frac{1}{\sqrt{2}}\end{array}\right]\left[\begin{array}{ccc}1 & 1 & 1 \\ 1 & 1 & -2 \\ 1 & -1 & 0\end{array}\right]\left[\begin{array}{c}L \\ M \\ S\end{array}\right] \ldots \ldots .(2)$

\section{b) Penyesuaian Tingkat Kecerahan Warna}

Citra warna dan citra greyscale memiliki perbedaan tingkat kecerahan yang cukup tinggi, hal ini dapat berpengaruh di dalam proses pewarnaan sehingga diperlukan adanya suatu proses luminance remapping,yaitu suatu proses menggeser dan menskalakan tingkat kecerahan citra warna agar sesuai dengan tingkat kecerahan citra greyscale. Terdapat beberapa tahapan dalam melaksanakan proses penyesuain tingkat kecerahan citra, adapun tahapan tersebut adalah sebagai berikut.

1. Membuat histogram tingkat kecerahan gambar warna.

2. Membuat histogram tingkat kecerahan gambar greyscale.

3. Melakukan proses luminance remapping.

c) Menghitung Statistik Pixel

Proses ini bertujuan untuk mencari kecocokkan antara citra warna dengan citra greyscale. Terdapat beberapa tahapan yang harus dilakukan untuk mencari kecocokkan antara citra warna dengan citra greyscale yaitu: 
1. Pemilihan sampel pixel warna pada citra warna

Sampel warna merupakan contoh pixel warna yang nantinya akan diambil nilai kromatik warnanya yang akan digunakan sebagai pigmen warna pixel pada citra greyscale.

2. Perhitungan statistik

Perhitungan statistik yang dimaksud disini adalah perhitungan mean (rata-rata) dan perhitungan standar deviasi (simpangan baku). Perhitungan statistik dilakukan pada kedua citra inputan. Pada citra warna, perhitungan dilakukan pada masing-masing sampel sedangkan pada citra greyscale dilakukan pada keseluruhan masing-masing pixel. Dalam perhitungan nilai rata-rata dan simpangan baku setiap pixel dilakukan dengan menggunakan matriks 5 × 5 .

\section{d) Mencocokan Pixel}

Setiap pixel pada citra greyscale dicocokkan dengan pixel sampel yang didapat dari citra warna. Proses pencocokan dilakukan dengan menghitung bobot rata-rata dan simpangan baku di sekelilingnya. Dengan menganggap rata-rata $(\mu)$ dan simpangan baku $(\sigma)$ tersebut sebagai kordinat, maka pixel gambar warna yang paling cocok adalah pixel yang memiliki jarak terpendek (d) dengan pixel gambar greyscale. Ilustrasi pencocokan pixel dapat dilihat seperti Gambar 3 berikut.

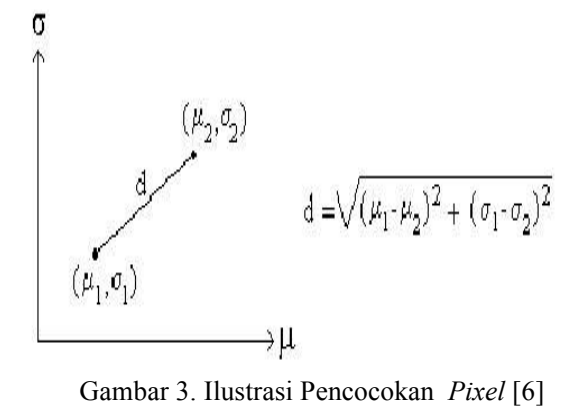

e) Pewarnaan Citra Greyscale

Ketika ditemukan pixel yang paling cocok, nilai kromatik $l$ dan $\beta$ ditransfer ke pixel target pada citra greyscale, sementara tingkat kecerahan pixel tetap disimpan.

Setelah proses pewarnaan di atas, maka citra greyscale yang telah memiliki warna dalam $l \alpha \beta$ color space harus diubah kembali ke RGB color space untuk menampilkannya. Perubahan ruang warna $l \alpha \beta$ ke dalam ruang warna RGB dibutuhkan matriks konversi berikut
$\left[\begin{array}{c}L \\ M \\ S\end{array}\right]=\left[\begin{array}{ccc}1 & 1 & 1 \\ 1 & 1 & -1 \\ 1 & -2 & 0\end{array}\right]\left[\begin{array}{ccc}\frac{\sqrt{3}}{3} & 0 & 0 \\ 0 & \frac{\sqrt{6}}{6} & 0 \\ 0 & 0 & \frac{\sqrt{2}}{2}\end{array}\right]\left[\begin{array}{c}\iota \\ \alpha \\ \beta\end{array}\right] \ldots \ldots \ldots \ldots(3)$
$\left[\begin{array}{l}R \\ G \\ B\end{array}\right]=\left[\begin{array}{ccc}4.4679 & -3.5873 & 0.1193 \\ -1.2186 & 2.3809 & -0.1624 \\ 0.0497 & -0.2439 & 1.2045\end{array}\right]\left[\begin{array}{c}L \\ M \\ S\end{array}\right] . .(4)$

III METODOLOGI

\section{A. Analisis Perangkat Lunak}

Pada sub bab analisis perangkat lunak ini, akan dipaparkan tahapan dari Softwarel System Development Life Cycle (SDLC) yang meliputi hal-hal berikut.

\section{Kebutuhan Perangkat Lunak}

Berdasarkan analisis terhadap pengembangan aplikasi konversi video digital greyscale menjadi video digital berwarna, maka terdapat beberapa proses yang dapat implementasikan, yaitu:

a. Melakukan ekstrasi dari video greyscale menjadi frame-frame dengan format bitmap dan sebuah file audio dengan format mp3.

b. Melakukan operasi perubahan ruang warna dari ruang warna $\mathrm{RGB}$ ke ruang warna $l \alpha \beta$ dan sebaliknya dari ruang warna $l \alpha \beta$ ke ruang warna RGB.

c. Melakukan penyesuaian tingkat kecerahan pixel dengan cara melakukan perataan histogram pada framegreyscale dan citra warna acuan dan melakukan proses spesifikasi histogram pada frame dan citra acuan hasil perataan histogram.

d. Melakukan pengambilan pixel sampel dari citra warna acuan dengan jumlah yang sesuai dengan yang di-input-kan user.

e. Melakukan penghitungan statistika pixel yang meliputi penghitungan rata-rata dan penghitungan standar deviasi pixel.

f. Melakukan pencocokan nilai pixel, pencocokan nilai pixel didasarkan atas nilai perhitungan pada operasi statistik.

g. Melakukan proses pewarnaan framegreyscale menjadi frame berwarna.

h. Melakukan penggabungan antara frame-frame yang sudah diwarnai dengan file audio menjadi sebuah video berwarna.

\section{Tujuan Pengembangan Perangkat Lunak}

Adapun tujuan dari pengembangan perangkat lunak aplikasi konversi video digital greyscale menjadi video digital berwarnaadalah sebagai berikut. 
a. Dapat melakukan ekstrasi dari video greyscale menjadi frame-frame dengan format bitmap dan sebuah file audio dengan format $\mathrm{mp} 3$.

b. Dapat melakukan operasi perubahan ruang warna dari ruang warna RGB ke ruang warna $l \alpha \beta$ dan sebaliknya dari ruang warna $l \alpha \beta$ ke ruang warna RGB.

c. Dapat melakukan penyesuaian tingkat kecerahan pixel dengan cara melakukan perataan histogram pada framegreyscale dan citra acuan dan melakukan proses spesifikasi histogram pada frame dan citra acuan hasil perataan histogram.

d. Dapat melakukan pengambilan pixel sampel dari citra warna acuan dengan jumlah yang sesuai dengan yang di-input-kan user.

e. Dapat melakukan penghitungan statistika pixel yang meliputi penghitungan rata-rata dan penghitungan standar deviasi pixel.

f. Dapat melakukan pencocokan nilai pixel, pencocokan nilai pixel didasarkan atas nilai perhitungan pada operasi statistik.

g. Dapat melakukan proses pewarnaan frameframegreyscale menjadi frame-frame berwarna.

h. Dapat melakukan penggabungan antara frameframe yang sudah diwarnai dengan file audio menjadi sebuah video berwarna.

3. Masukan dan Keluaran Perangkat Lunak Adapun masukan dan keluaran dari perangkat lunak aplikasi konversi video digital greyscale menjadi video digital berwarna,adalah sebagai berikut.

\section{a. Masukan Perangkat Lunak}

> Video greyscale dengan format AVI, FLV, WEBM, MKV, MPEG, MP4, dan WMV.

$>$ Parameter jumlah frame per-detik (fps) untuk proses ekstrasi video.

$>$ Citra acuan pewarnaan dengan format bitmap (*.bmp) 24 bit.

> Parameter jumlah pixel sampel yang akan digunakan sebagai acuan pewarnaan.

$>$ Format file video output hasil pewarnaan video greyscale.

\section{b. Keluaran Perangkat Lunak}

Frame hasil ekstrasi video greyscale dengan format bitmap (*.bmp).

$>$ Audio hasil ekstrasi video dengan format mp3.
Frame hasil pewarnaan dengan format bitmap (*.bmp).

$>$ Video digital berwarna dengan format yang dipilih oleh user.

\section{Perancangan Perangkat Lunak}

Terdapat beberapa tahapan dalam perancangan perangkat lunak aplikasi konversi video digital greyscale menjadi video digital berwarna. Adapun tahapan-tahapan tersebut yaitu.

\section{a. Batasan Perancangan Perangkat Lunak}

Masalah yang akan dibahas pada skripsi ini dibatasi pada hal-hal sebagai berikut.

1. Video digital greyscale yang dimaksud adalah video yang apabila diekstrak akan terdiri dari frame-frame yang memiliki warna skala keabuan (greyscale) berekstensi bitmap (*.bmp) 24 bit.

2. Format video masukan berupa AVI, FLV, WEBM, MKV, MPEG, MP4, dan WMV.

3. Citra warna/ acuan menggunakan format RGB - 24 bit dan berekstensi BMP, PNG dan JPEG/ JPG.

\section{b. Alur Kerja Perangkat Lunak}

Alur kerja perangkat lunak konversi video digital greyscale menjadi video digital berwarna dimulai dari user meng-input-kan video greyscale, dimana video greyscale akan diekstrak menjadi frame-frame greyscale dan file audio. Setelah proses ekstrak selesai dilanjutkan ke proses pewarnaan frame, pewarnaan frame dilakukan secara frame by frame dengan warna acuan diperoleh dari citra warna acuan yang di-input-kan user. Proses pewarnaan akan dilakukan pada semua frame hasil ekstraksi. Setelah semua frame diwarnai, kemudian dilanjutkan ke tahap rendering frame-frame hasil pewarnaan dan audio hasil ekstraksi menjadi video digital yang sudah berwarna (true color). Alur kerja dari aplikasi konversi video digital greyscale menjadi video digital berwarna digambarkan dalam flowchart pada Gambar 4 dan Gambar 5 merupakan flowchart dari proses pewarnaan yang dijabarkan lebih detail. 


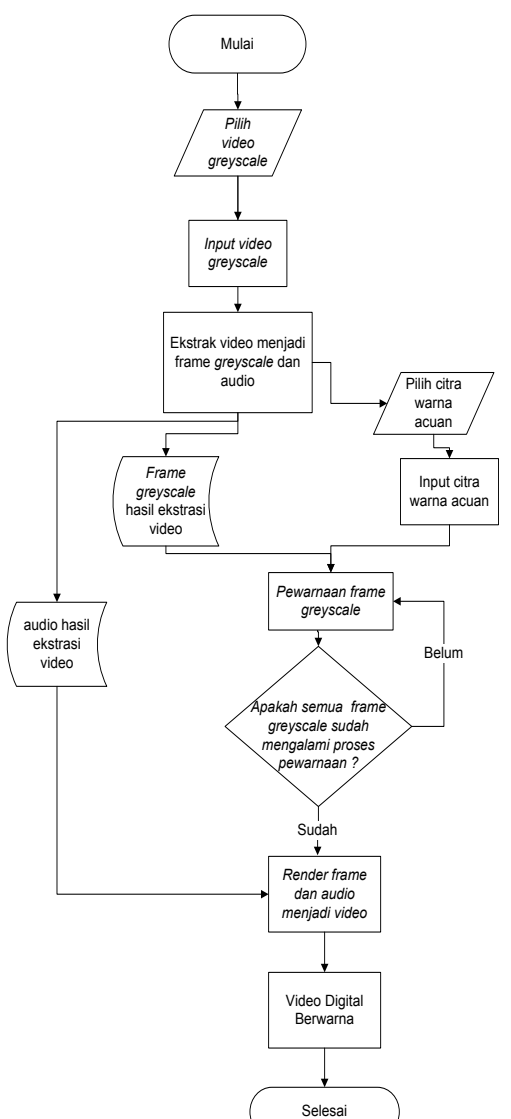

Gambar 4. Flowchart Aplikasi Konversi Video Digital Greyscale Menjadi Video Digital Berwarna

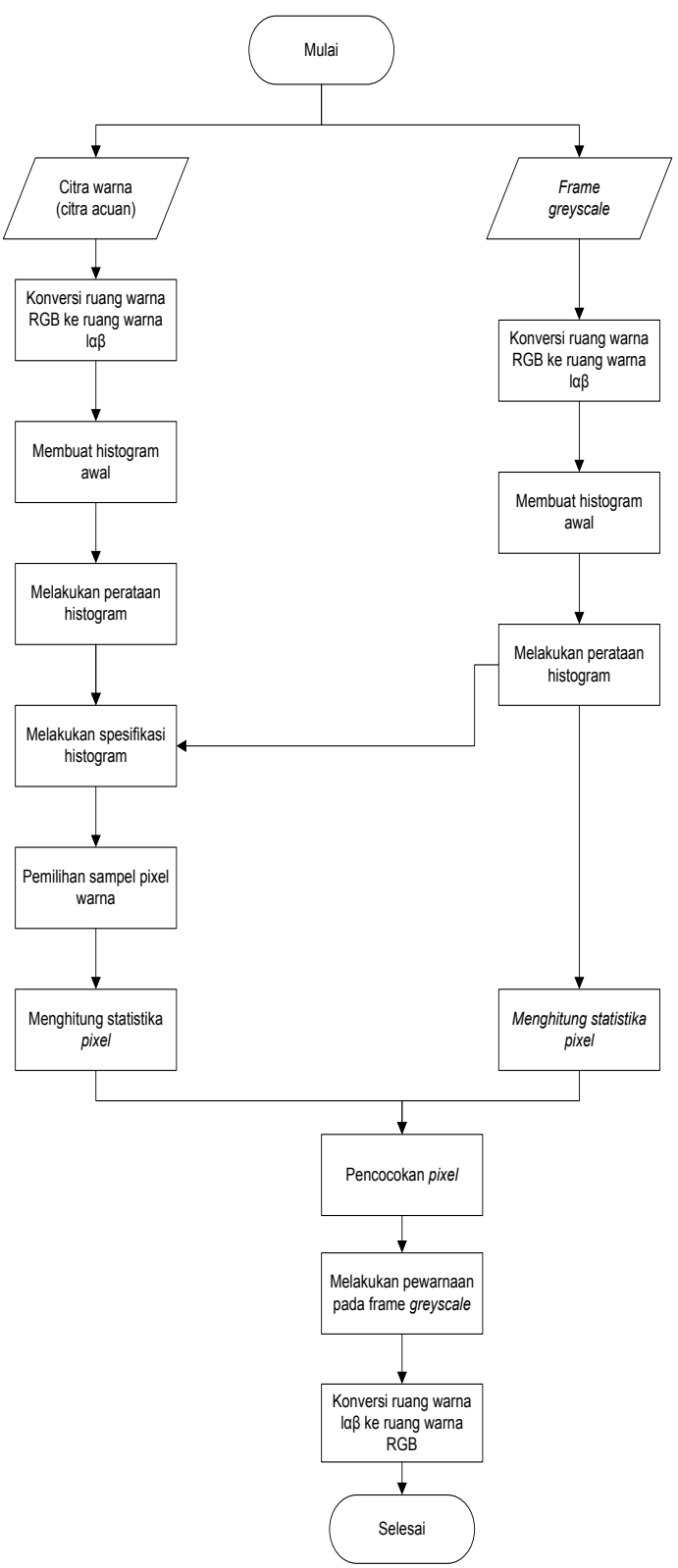

Gambar 5. Flowchart Proses Pewarnaan Aplikasi Konversi Video Digital Greyscale Menjadi Video Digital Berwarna

c. Perancangan Arsitektur Perangkat Lunak

Pada tahapan ini menggambarkan bagianbagian modul, struktur ketergantungan antar modul, dan hubungan antar modul dari perangkat lunak yang dibangun. Pada bagian ini terdapat structure chart dan flowchart sebagai kendali fungsional yang digambarkan seperti Gambar 6 untuk perangkat lunak aplikasi konversi video digital greyscale menjadi video digital berwarna. 


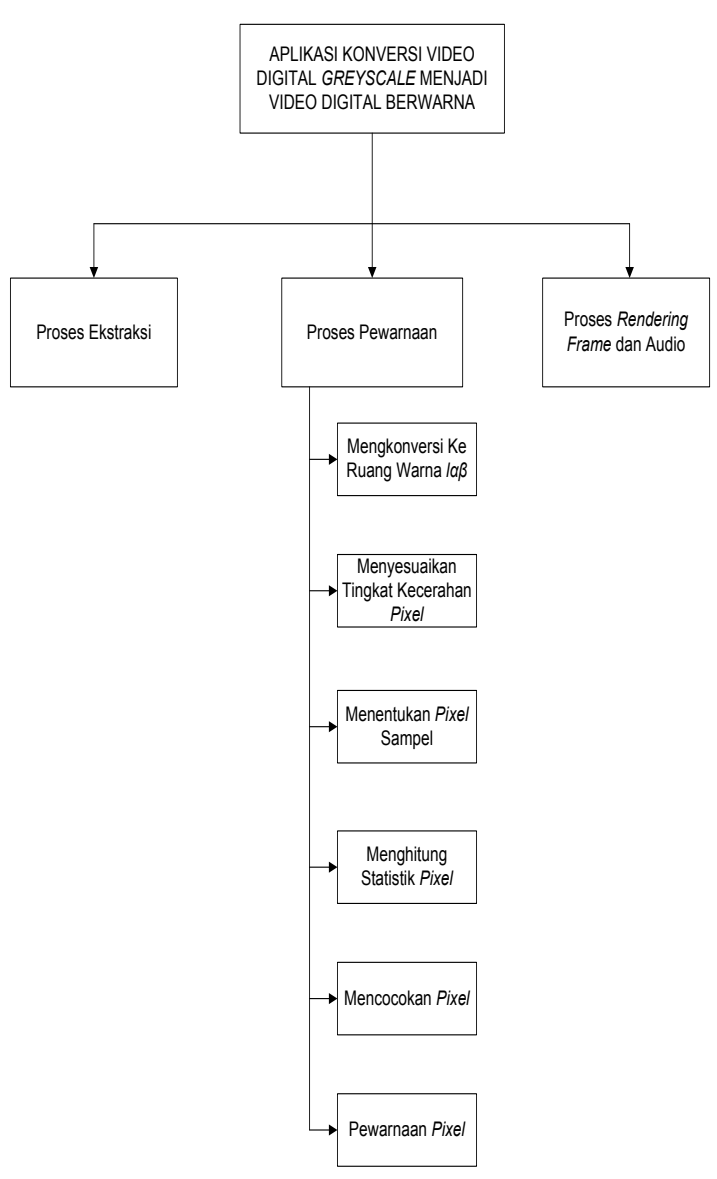

Gambar 6. Structure Chart Aplikasi Konversi Video Digital Greyscale Menjadi Video Digital Berwarna

Dari Gambar 6 kita dapat mengetahui bahwa dalam aplikasi yang akan dikembangkan terdapat tiga proses utama dan 6 sub proses dari proses pewarnaan. Setiap sub proses dari proses pewarnaan merupakan implementasi dari metode Global Image Matching. Penggunaan metode Global Image Matching pada pengembangan aplikasi ini disebabkan karena metode Global Image Matching merupakan teknik pentransferan warna yang paling efisien jika dibandingkan dengan teknik pentransferan warna yang lain, misalnya teknik pentransferan dengan menggunakan swatches.

\section{d. Perancangan Struktur Data Perangkat Lunak}

Struktur data utama yang digunakan dalam perangkat lunak aplikasi konversi video digital greyscale menjadi video digital berwarna ini adalah struktur data yang terdapat pada bahasa pemrograman java yaitu matriks arrayofarrayofshort, arrayofarrayofinteger,matriks array of array of double, larik arrayofinteger, larik array of double,string, bufferedImage dan integer. Sedangkan struktur data bentukan meliputi type dan objek. Tipe data objek pada perangkat lunak aplikasi konversi video digital greyscale menjadi video digital berwarna dapat berupa tampilan GUI (Graphic Unit Interface). Objek untuk tampilan GUI yang digunakan adalah objek-objek yang terdapat pada bahasa pemrograman java dengan menggunakan editor Netbeans, diantaranya yaitu Jframe, Jinternalframe, Jtabbedpane, Jpopupmenu, Jpanel, Jlabel, Jbutton, Jtextfield, Jcheckbox, Jprogressbar, Jradiobutton, Jfilechooser dan Jspinner, Jscrollpane.

\section{e. Perancangan Antar Muka Perangkat Lunak}

Perancangan antar muka perangkat lunak bertujuan untuk menggambarkan bentuk rancangan atarmuka perangkat lunak yang meliputi rancangan layar utama, racangan layar ekstrak video, rancangan layar pewarnaan frame, rancangan layar rendering dan rancangan layar hasil pewarnaan.

\section{PEMBAHASAN}

\section{A. Lingkungan Implementasi Perangkat Lunak}

Perangkat lunak konversi video digital greyscale menjadi video digital berwarna dikembangkan pada lingkungan perangkat keras komputer (notebook) yang memiliki spesifikasi sebagai berikut:

a. Monitor 14 inci.

b. Processor Intel Core 2 Duo T6670 2.20 GHz.

c. Random access memory (RAM) $2.00 \mathrm{~GB}$.

Untuk lingkungan perangkat lunak, aplikasi konversi video digital greyscale menjadi video digital berwarna dibangun pada lingkungan sistem operasi Ubuntu 12.04.1 LTS. Sedangkan untuk bahasa pemrograman yang digunakan adalah bahasa pemrograman Java dengan java version 1.7.0 10 dan editor yang digunakan adalah Netbeans 7.2.1. Selain itu peneliti juga menggunakan aplikasi FFmpeg untuk proses pengolahan video.

\section{B. Implementasi Arsitektur Perangkat Lunak Konversi Video Digital Greyscale Menjadi Video Digital Berwarna \\ Structure chart perangkat lunak aplikasi pewarnaan citra greyscale diimplementasikan menggunakan bahasa pemrograman Java dengan}


editorNetbeans 7.2.1. Tabel 1 berikut ini merupakan tabel pemetaan class implementasi.

\begin{tabular}{|c|c|c|}
\hline $\begin{array}{l}\text { Bagian } \\
\text { Peranca- } \\
\text { ngan } \\
\text { Arsitektur }\end{array}$ & $\begin{array}{l}\text { Unit } \\
\text { Impleme } \\
\text { ntasi }\end{array}$ & $\begin{array}{l}\text { Penjelasan Unit } \\
\text { Implementasi }\end{array}$ \\
\hline $\begin{array}{l}\text { Proses } \\
\text { Ekstrak }\end{array}$ & $\begin{array}{l}\text { ClassUta } \\
\text { ma.java }\end{array}$ & $\begin{array}{l}\text { Pada class ini terdapat } \\
\text { method } \\
\text { mengekstrak untuk } \\
\text { greyscale yang di-input- } \\
\text { kan oleh user menjadi } \\
\text { frame-frame dengan } \\
\text { format bitmap dan } \\
\text { menjadi sebuah file audio } \\
\text { dengan format mp3. }\end{array}$ \\
\hline \multirow[t]{4}{*}{$\begin{array}{l}\text { Proses } \\
\text { Pewarna- } \\
\text { an }\end{array}$} & $\begin{array}{l}\text { ClassUta } \\
\text { ma.java }\end{array}$ & $\begin{array}{l}\text { Pada class ini terdapat } \\
\text { beberapa method untuk } \\
\text { meminta input-an dari } \\
\text { user yang terkait dengan } \\
\text { proses pewarnaan }\end{array}$ \\
\hline & $\begin{array}{l}\text { ImagePr } \\
\text { ocessing. } \\
\text { java }\end{array}$ & $\begin{array}{lr}\text { Pada class } & \text { ini } \\
\text { diimplementasikan } & \\
\text { method-method } & \text { untuk } \\
\text { melakukan } & \text { proses } \\
\text { pewarnaan yang } & \text { sesuai } \\
\text { dengan metode } & \text { Global } \\
\text { Image Matching. } & \\
\end{array}$ \\
\hline & $\begin{array}{l}\text { ImageM } \\
\text { atricess.j } \\
\text { ava }\end{array}$ & $\begin{array}{l}\text { Pada class ini } \\
\text { diimplementasikan } \\
\text { method-method untuk } \\
\text { melakukan pembacaan file } \\
\text { citra, untuk mendapatkan } \\
\text { nilai RGB dari suatu citra, } \\
\text { untuk mengubah nilai- } \\
\text { nilai RGB menjadi suatu } \\
\text { file citra. }\end{array}$ \\
\hline & $\begin{array}{l}\text { Image_P } \\
\text { review.ja } \\
\text { va }\end{array}$ & $\begin{array}{l}\text { Class ini digunakan untuk } \\
\text { menampilkan hasil dari } \\
\text { testing pewarnaan frame } \\
\text { greyscale. }\end{array}$ \\
\hline $\begin{array}{l}\text { Proses } \\
\text { Rendering }\end{array}$ & $\begin{array}{l}\text { ClassUta } \\
\text { ma.java }\end{array}$ & $\begin{array}{l}\text { Pada class } \\
\text { ClassUtama.java terdapat } \\
\text { method untuk } \\
\text { menggabungkan frame- } \\
\text { frame hasil pewarnaan dan } \\
\text { file audio menjadi sebuah } \\
\text { video. }\end{array}$ \\
\hline
\end{tabular}

\section{Implementasi Layar Antarmuka Perangkat Lunak}

Rancangan layar antarmuka perangkat lunak aplikasi konversi video digital greyscale menjadi video digital berwarna diimplementasikan menggunakan class-class yang terdapat pada frame di editor Netbeans 7.2.1IDE. Gambar 7 sampai Gambar 11 merupakan implementasi dari rancangan antarmuka yang direncanakan.

\section{Form Utama Perangkat Lunak}

Form utama merupkan form yang pertama kali tampil saat aplikasi dijalankan. Dalam aplikasi konversi video digital greyscale menjadi video digital berwarna, form utama dibagi menjadi tiga $t a b$ yaitu $t a b$ ekstrak video, $t a b$ pewarnaan frame dan tabrendering. Implementasi form utama seperti pada Gambar 7 berikut.

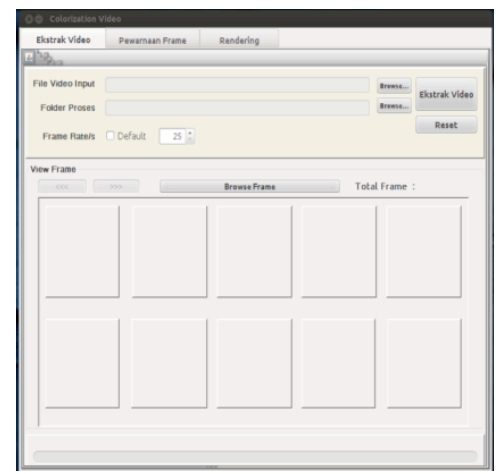

Gambar 7. Form Utama Perangkat Utama

\section{Tab Ekstrak Video}

Tab ekstrak video merupakan tempat user untuk melakukan proses ekstrak video greyscale menjadi frame-frame dan file audio. File-file frame hasil dari ekstraksi video akan akan diberi nama Frame 1, Frame 2...Frame n, dimana $n$ merupakan total frame hasil ekstraksi. Total frame diperoleh dari lama durasi video dalam detik dikali dengan nilai frame rate/second yang di-input-kan user. Setelah proses ekstrak selesai, frame-frame akan ditampilkan pada panel view frame. pada Gambar 8 merupakan implementasi dari $t a b$ ekstrak video.

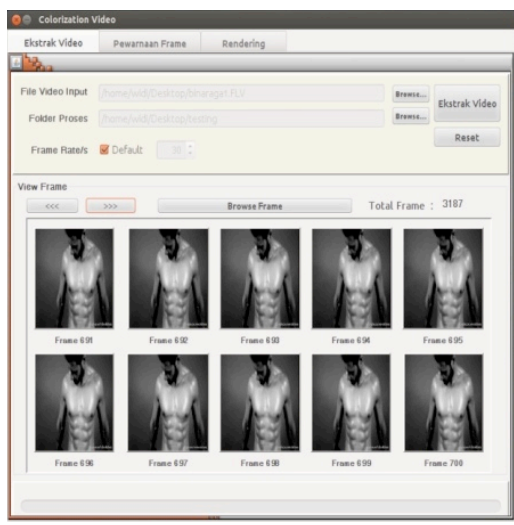

Gambar 8. Tab Ekstrak Video 


\section{Layar Tab Pewarnaan Frame}

Tab pewarnaan frame merupakan implementasi dari metode Global Image Matching, dimana user dapat melakukan proses pewarnaan frame-frame hasil dari ekstraksi video greyscale. Dalam tab pewarnaan frame terdapat bagian untuk melakukan testing pewarnaan pada salah satu frame yang akan diwarnai, sehingga user dapat menentukan citra warna acuan yang tepat untuk proses pewarnaan. Proses pewarnaan pada $t a b$ pewarnaan frame dapatdilakukan pada semua frame ataubeberapa frame saja dengan memilih option "Terapkan Pada". Adapun implementasi dari tab pewarnaan frame adalah seperti Gambar 9.

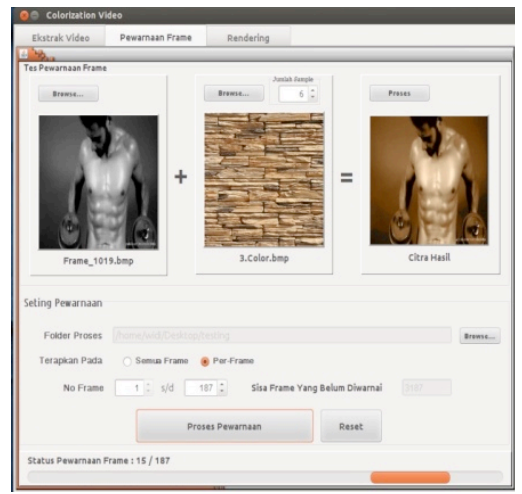

Gambar 9. Tab Pewarnaan Frame

\section{Form Hasil Pewarnaan}

Form hasil pewarnaan adalah form yang digunakan untuk menampilkan lebih detail frame hasil testing pewarnaan. Pada form ini pengguna dapat melakukan zoom in, zoom out dan pengembalian ke ukuran semula dari frame yang dilihat. Gambar 10 adalah implementasi dari form hasil pewarnaan.

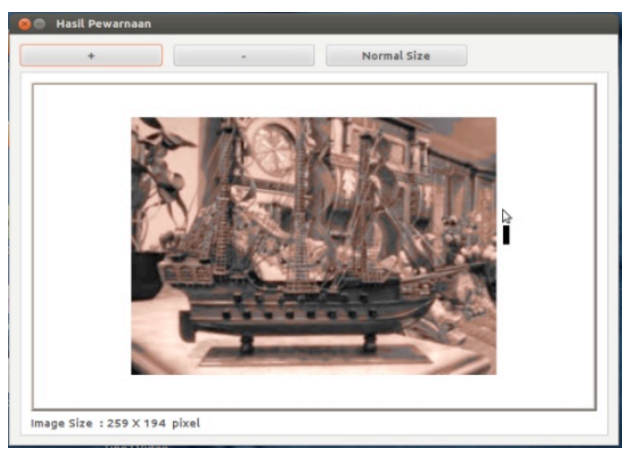

Gambar 10. Form Hasil Pewarnaan

\section{Tab Rendering}

$T a b$ ini merupakan $t a b$ yang digunakan dalam penggabungan frame-frame hasil proses pewarnaan dengan audio dari hasil ekstraksi video greyscale menjadi video digital berwarna.Proses render baru bisa dilakukan jika semua frameframe hasil ekstraksi diwarnai. Dalam tabrendering, user akan memilih format filevideo yang tersedia untuk menjadi keluaran dari aplikasi konversi video digital greyscale menjadi video digital berwarna.Format file video yang dapat dipilih adalah AVI , FLV, WEBM, MKV, MPEG, MP4, dan WMV.Gambar 11. merupakan implementasi dari tabrendering.

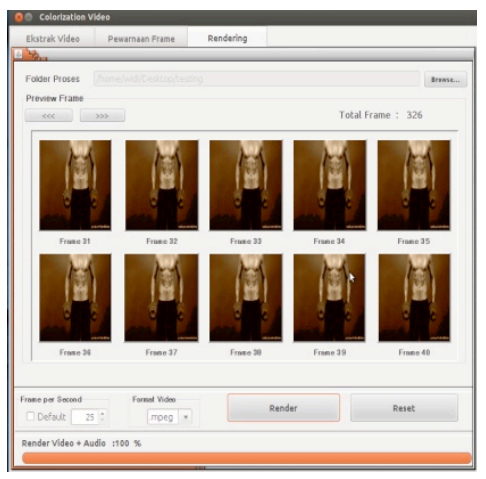

Gambar 11. Tab Rendering

\section{Pengujian Perangkat Lunak}

Secara umum hasil pengujian fungsional menunjukan bahwa sistem sudah dapat menangani data masukan yang tidak valid dan valid dan dapat melakukan proses pewarnaan video greyscale menjadi video berwarna dengan baik. Berikut akan ditampilkan hasil perbandingan frame-frame hasil pengujian aplikasi konversi video digital greyscale menjadi video digital berwarna.

\section{Video "Surfer (Old Times)" \\ Video "Surfer (Old Times)" dapat anda lihat di situs Youtube dengan alamat} http://www.youtube.com/watch? $\mathrm{v}=$ YqhUDHLAs U. Video ini berdurasi 46 detik. Dengan nilai fps yaitu 26, frame yang didapat setelah dilakukan ekstraksi yaitu 1216 frame dengan resolusi frame 320 x 240 pixel. Pada proses pewarnaan, pewarnaan dilakukan pada semua frame yang mengacu pada 1 citra warna acuan. Waktu yang dibutuhkan untuk melakukan pewarnaan pada 1216 frame yaitu 335711 milidetik, sehingga waktu proses per frame-nya yaitu 276,08 milidetik. Tabel 2 berikut menampilkan 
perbandingan beberapa frame sebelum dah sesudah diwarnai.

Tabel 2. Hasil Perbandingan Frame Sebelum Diwarnai dan Setelah Diwarnai pada Video " Surfer (Old Times)"

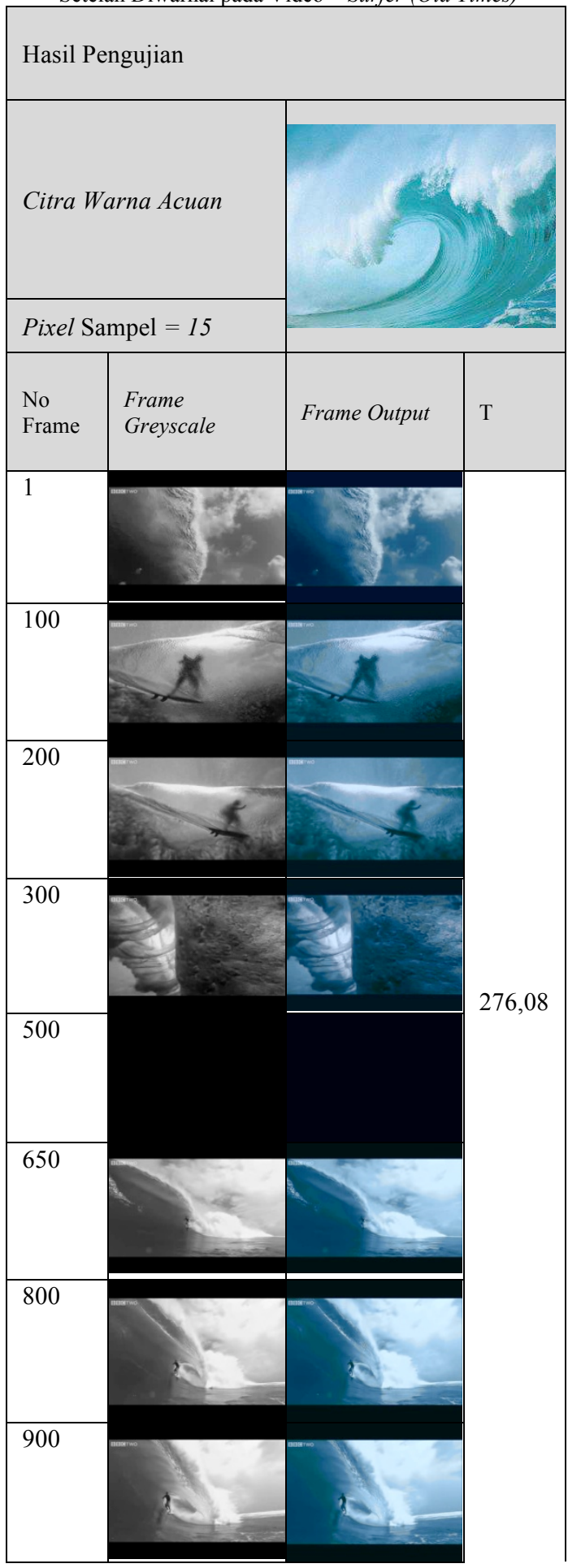

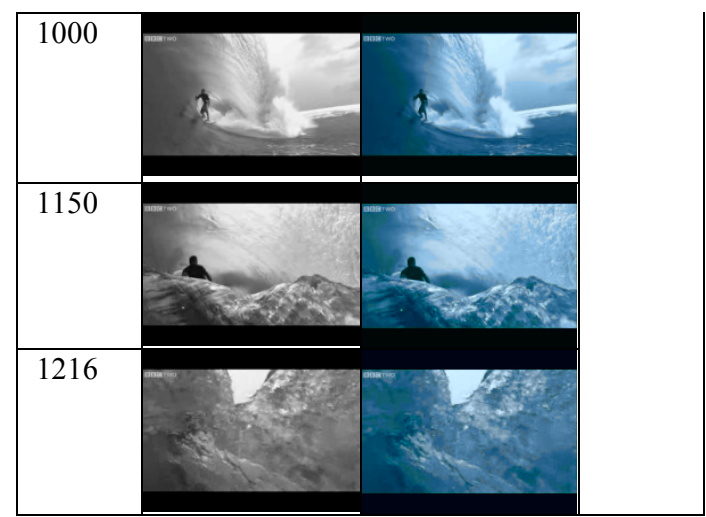

Ket : $\mathrm{T}=$ waktu proses per frame (milidetik)

\section{Video "Forest Freeride"}

File video "Forest Freeride" merupakan video yang berdurasi 2 menit 7 detik. Video "Forest Freeride" dapat anda saksikan di situs Youtube dengan alamat http://www.youtube.com/watch?v=3u Vi4Eb nQ. Setelah dilakukan ekstraksi dengann fps sama dengan 30, didapatkan frame sebanyak 3812 frame dengan resolusi 426 x 240 pixel. Pada proses pewarnaan video "Forest Freeride" ini menggunakan beberapa citra warna acuan. Pemakain citra warna acuan yang lebih dari satu disebabkan karena pada video ini terdiri dari latar tempat yang berbeda-beda. Tabel hasil perbandingan frame sebelum dah sesudah diwarnai ditunjukan pada Tabel 3 berikut.

Tabel 3. Hasil Perbandingan Frame Sebelum Diwarnai dan Setelah Diwarnai pada Video "Forest Freeride"

\begin{tabular}{|c|c|c|c|c|c|}
\hline \multirow[b]{2}{*}{ No } & \multicolumn{2}{|l|}{ Input } & \multirow[b]{2}{*}{$\begin{array}{l}\text { Frame } \\
\text { Output }\end{array}$} & \multirow[b]{2}{*}{$\mathrm{S}$} & \multirow[b]{2}{*}{$\mathrm{T}$} \\
\hline & $\begin{array}{l}\text { Frame } \\
\text { Greyscale }\end{array}$ & $\begin{array}{l}\text { Citra } \\
\text { Warna } \\
\text { Acuan }\end{array}$ & & & \\
\hline \multirow[t]{2}{*}{104} & & & & \multirow{7}{*}{20} & \multirow{7}{*}{632} \\
\hline & Frest Freeride & & Forest Freeride & & \\
\hline 140 & & & (1) & & \\
\hline & & & & & \\
\hline & Forest Freeride & & Forest Freeride & & \\
\hline \multirow[t]{2}{*}{200} & & & & & \\
\hline & Forest Freeride & & Frest Feeride & & \\
\hline
\end{tabular}




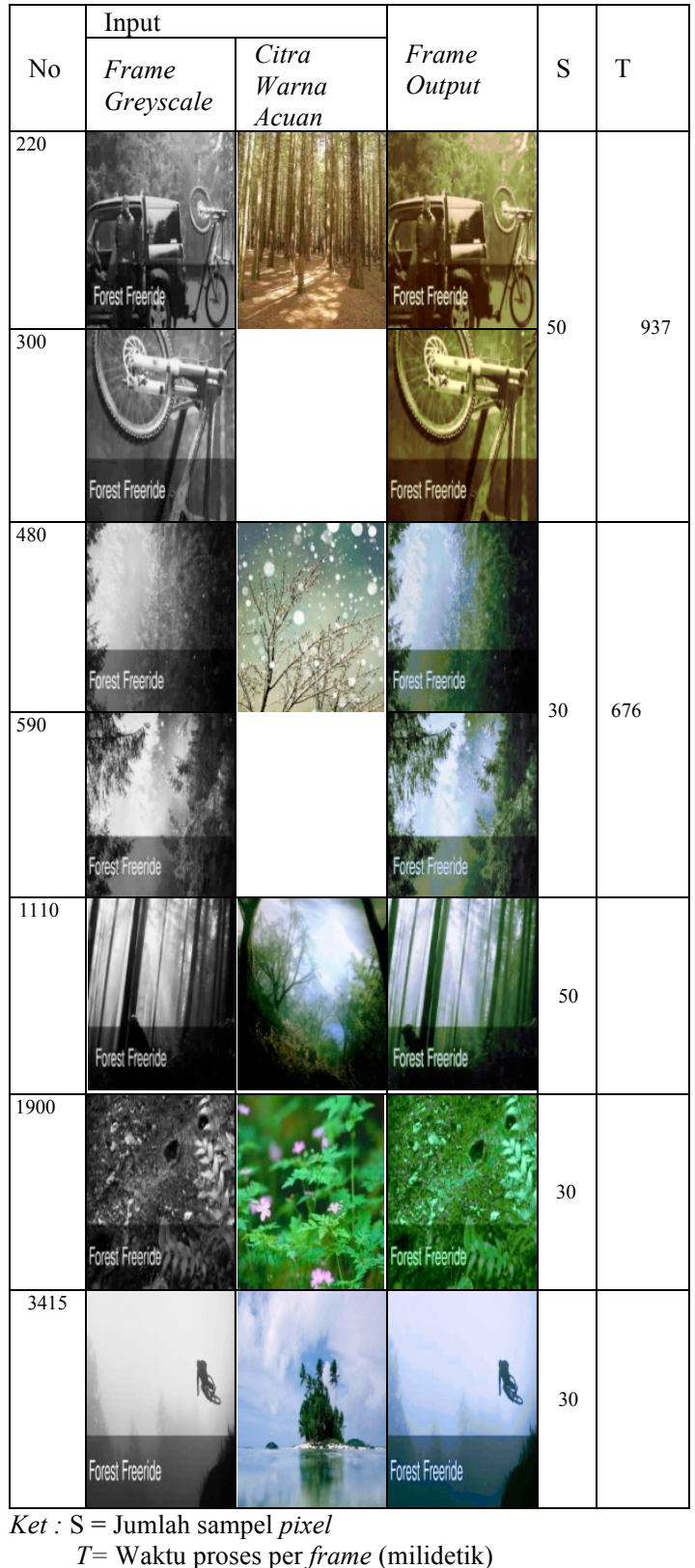

\section{E. Evaluasi Hasil Pengujian}

Berdasarkan hasil pengujian di atas, diketahui bahwa aplikasi konversi video digital greyscale menjadi video digital berwarna sudah mampu melakukan proses pewarnaan pada video greyscale. Hal ini dibuktikan dengan terjadinya perubahan warna pada frame greyscale yang awal mulanya hanya memiliki nuansa warna keabuan saja tapi setelah dilakukan proses pewarnaan maka frame yang dihasilkan memiliki warna yang beragam (true color). Keberhasilan sistem sangat ditentukan oleh citra warna acuan yang di-inputkan. Citra warna acuan yang memiliki tingkat kecerahan yang yang mendekati tingkat kecerahan frame greyscale akan menyebabkan hasil pewarnaan lebih baik jika dibandingkan dengan citra warna acuan yang memilliki tingkat kecerahan yang sangat berbeda dengan frame greyscale.

\section{PENUTUP}

A. Simpulan

Berdasarkan penelitian yang telah dilakukan diperoleh simpulan sebagai berikut.

1. Implementasi metode Global Image Matching pada aplikasi konversi video digital greyscale menjadi video digital berwarna menghasilkan suatu aplikasi yang mampu melakukan pewarnaan video greyscale dengan cepat dan mudah sehingga dapat dilakukan oleh semua orang.

2. Kecepatan dalam pewarnaan video greyscale sangat ditentukan oleh jumlah pixel sampel yang di-input-kan.

3. Hasil pewarnaan video yang diperoleh sangat ditentukan oleh citra warna acuan yang diinput-kan.

Untuk pengembangan lebih lanjut dari aplikasi konversi video digital greyscale menjadi video digital berwarna, adapun saran yang dapat diberikan adalah sebagai berikut.

a. Adanya pengembangan algoritma penyesuian tingkat kecerahan yang lebih spesifik sehingga menghasilkan tingkat kecerahan frame greyscale dan citra warna acuan akan memiliki lebih baik dan nantinya akan berimbas pada hasil pewarnaan yang lebih bagus.

$b$. Adanya pengembangan algoritma yang dapat melakukan restorasi pada frame hasil pewarnaan, sehingga dapat meminimalisir bercak-bercak yang dihasilkan dari proses pewarnaan frame.

c. Adanya pengembangan algoritma yang dapat mendeteksi bentuk, sehingga kita dapat menentukan dengan lebih tepat objek yang akan diwarnai dari suatu frame hasil ekstraksi.

\section{REFERENSI}

[1] Pusat Pengembangan Bahan Ajar Universitas Mercu Buana . 2011. Video \& Televisi. Tersedia pada http://kk.mercubuana.ac.id/files/92052-3574637347358.doc.

[2] Putra, Darma.2010. Pengolahan Citra Digital. Yogyakarta: Andi. 
[3] Budiman, Asep. 2009. Aplikasi Steganography pada Video dengan Metode Least Significant Bit (LSB). Skripsi (tidak diterbitkan). Teknik Informatika S1, Universitas Indonesia. Tersedia

pada

http://elib.unikom.ac.id/gdl.php?mod=browse\&op=read\&i $\mathrm{d}=$ jbptunikompp-gdl-asepbudima-18351.

[4] Andikaputra, Gusti Bagus Agung Pradnya. 2011 Karakteristik Video Digital. Tersedia pada http://digilib.ittelkom.ac.id/index.php?option=com content \&view $=$ article \&id=866:karakteristik-videodigital\&catid=21:itp-informatika-teori-danpemograman\&Itemid=14 (diakses pada tanggal 20 Desember 2012)

[5] http://id.wikipedia.org/wiki/FFmpegpdf (diakses tgl 18 Desember 2012)
[6] Dewi, Lilyana. 2003. Perencanaan Dan Pembuatan Aplikasi Untuk Transfer Warna Ke Gambar Greyscale Dengan Metode Global Image Matching. Skripsi (tidak diterbitkan). Teknik Informatika S1, Universitas Kristen Petra. Tersedia pada http://dewey.petra.ac.id/jiunkpe dg 1519.html.

[7] Welsh, et.al. 2002. "Transferring Color to Greyscale Image". Tersedia pada www.cse.iitd.ernet.in/ pkalra/cs1783/assignment1/colorize .pdf (diakses tgl 17 Desember 2012).

[8] Putra, I Made Agus Wirahadi. 2012. Pengembangan Aplikasi Citra Digital Untuk Mengubah Citra Greyscale Menjadi Citra Berwarna. Skripsi (tidak diterbitkan). Jurusan Pendidikan Teknik Informatika, Undiksha Singaraja. 